\section{Homosexuality and Anorexia Nervosa: An Explorative Study on Personality Traits}

\section{Abstract}

Background: The relationship between anorexia nervosa in males and homosexuality is debated. A higher rate of Eating Disorders (EDs) was found in homosexual than in heterosexual men population. Since anorexia nervosa in men relates with a specific personality profile, homosexual men may share personality features with men affected with anorexia nervosa which may represent risk factors for the ED's outburst. Nevertheless, they have never been compared with the same instrument. The Temperament and Character Inventory $(\mathrm{TCl})$ was widely applied in the study of EDs.

Methods: This study compares personality traits, assessed with the $\mathrm{TCl}$ in a group of males with anorexia nervosa $(n=21)$ with two control groups; heterosexual $(n=51)$ and homosexual $(n=23)$. A discriminant analysis was performed.

Results: Men with anorexia nervosa and homosexual controls display a higher harm avoidance and a lower self-directedness compared with heterosexual controls. Men with anorexia nervosa also display a lower reward dependence compared with homosexual controls and a lower cooperativeness compared with both control groups.

Conclusions: A relationship between the personality traits of men with anorexia nervosa and homosexual orientation may exist. Nevertheless, the low reward dependence and the low cooperativeness, which are the most specific characteristics of men with anorexia nervosa, are not linked to the homosexual orientation. Homosexual controls share with men with anorexia nervosa nonspecific personality traits that may indicate a common susceptibility to body's dissatisfaction, depression and stress.

Keywords: Anorexia nervosa; Male; Personality; Temperament; Character homosexuality

\section{Federico Amianto, Dorati Gabriela, Angela Spalatro, Giovanni Abbate-Daga and Secondo Fassino}

\author{
Department of Neurosciences, Psychiatry \\ Section, Service for Eating Disorders, \\ University of Torino, Italy
}

\section{Corresponding author:}

Federico Amianto

\section{federico.amianto@unito.it}

Professor, Department of Neuroscience, Psychiatry Section, University of Torino, Italy.

Tel: +39-011-6638070

Citation: Amianto F, Gabriela D, Spalatro A, et al. Homosexuality and Anorexia Nervosa: An Explorative Study on Personality Traits. Acta Psychopathol. 2016, 2:5.

\section{Introduction}

Although Anorexia Nervosa (AN) affects both sexes, the prevalence of $A N$ is higher in females [1]. In fact Eating Disorders (EDs) display a higher prevalence in female gender among all mental disorders [2]. Hence, many studies have been performed on the female ED population while our knowledge about men with AN is still incomplete [3]. In addition, studies of men with AN are mainly retrospective and they're hampered by a low number of patients or limited to the observation of diagnostic features, clinical characteristics, and epidemiology [4].
The symptomatic expression of anorexia is similar between the genders [1,5]. However, some clinical differences are described, such as lower age of onset, psychiatric comorbidity, and eating psychopathology in male subjects $[6,7,8]$, more extreme expectancies on body weight in female subjects $[8,9]$ and specific personality traits with a lower Reward Dependence (RD) and a lower cooperativeness in males in the Temperament and Character Inventory (TCI) $[10,11]$. Some reports support the hypothesis of at least partially different pathogenic roots for the female vs. male forms of the disorder $[9,11,12]$.

The reason of such a different gender-related distribution of 
AN is still obscure and may also include biases on assessment and diagnostic criteria $[3,8]$. Nevertheless, the distribution rate among genders suggests that female gender represents a specific risk factor for the expression of an ED, according to the current diagnostic criteria. The specific personality and emotion regulation features that differentiate genders [13] may be particularly relevant for the way in which the individual perceives and elaborates those internal, relational and environmental pressures that contribute to the development of the ED.

For this reason, one of the most considered and consistent risk factor for men to develop an ED may be the individual's sexual orientation and its relationship with specific personality features, relevant to the pathogenesis of the $\operatorname{ED}[6,14]$. A support to this hypothesis is the evidence that male homosexuality and bisexuality have been evidence to be specific risk factors for the expression of AN and other EDs [14]. In fact, researchers have found a greater incidence of homosexual and bisexual behaviors in patients affected by EDs [6] and a greater distortion of the eating style and in the relationship with body image in groups of homosexual men $[15,16]$, even when their scores are controlled with respect to the self-esteem and depression [14] or the peer pressure [16]. In contrast, homosexual women display the same levels of eating psychopathology [17] and seem to be less worried about their body shape [18] compared with heterosexual controls. Moreover, recent findings strongly associate the risk of an ED to body dissatisfaction in homosexual men [16]. Only few authors partially disagree, maintaining that the link between male homosexuality and EDs is weak [19].

Meyer and coworkers [12] and Murnen and Smolak [20] interpreted this complex debate, maintaining that an ED would be a pathologic feature of femininity (risk factor) with respect to masculinity (protective factor). The homosexual orientation could be also a generic stressor itself resulting in isolation, stigma, and violent social discrimination, which may facilitate the expression of mental disorders, including EDs [21].

Some evidences support that homosexual men display character fragility and high susceptibility to stress [22] and unusual aggressive patterns [23] than heterosexual subjects. These characteristics are consistent with the high Harm Avoidance (HA) and the low RD, self-directeness and cooperativeness of men with AN $[10,11]$. Nevertheless personality traits of homosexual men have never been studied with the $\mathrm{TCl}$ or other dimensional instruments for personality assessment, so neither a direct nor an indirect comparison with men with $\mathrm{AN}$ is possible at the moment.

The present study assess the temperament and character profile of men with $\mathrm{AN}$ and compare it with groups of homosexual and heterosexual men. This is to test the hypothesis of a specific affinity between men affected by AN and the homosexual men personality profile.

\section{Methods}

\section{Subjects}

All patients affected by AN (21 men) consecutively admitted to the ED unit at the Neurosciences Department of Turin University in two years were recruited consecutively for this study. Two control groups, matched for sex, ethnicity, and educational level were recruited.

Heterosexual men were selected from a database of the University of Torino, including more than $900 \mathrm{TCls}$ which were selected previously with respect to the other two samples, for various research purposes. These tests were administered to healthy white men and women, aged 18 to 65 years, belonging to different social backgrounds, who were previously selected for the absence of Axis I and II disorders and for the absence of clinical medical conditions by means of SCID and clinical interview.

The homosexual control group was recruited from a gay association in Torino that agreed to cooperate with our center with the mediation of one of their associates.

Inclusion criteria for all subjects were: 1) male gender; 2) age over 18 year olds; 3 ) educational level over 10 years; 4 ) adequate comprehension of Italian language. All those subjects who displayed clinically relevant Axis I mental disorders (psychosis, bipolar disorder, major depression, OCD, PTSD) or mental retardation have been excluded for the possible interference with the assessment of personality traits.

As concerns the affected probands they were included: 1) all the subjects who displayed a full diagnosis of AN according to DSM criteria; 2) who filled in the TCl correctly; 3) who gave their written informed consent to the study. Patients with AN restrictor ( 7 men) and AN binge-purging (14 men) meeting DSM$I V$ [2] criteria at the moment of the assessment were included in the study. Among the men with anorexia nervosa, 4 (25\%) had previous homosexual experiences or thoughts, but none defined himself as homosexual. Among the subjects included in the study, $6(29 \%)$ displayed psychiatric comorbidity with minor psychiatric disorder (1 minor depression, 3 cannabinoid and/or alcohol abuse, 2 both). The mean age of male patients with AN was 27.24 years $(S D=5.73$; range, $18-35$ years). The average educational level of male patients with $A N$ was 12.4 years $(S D=3.5)$ of formal education. The mean BMI was 16.4 (SD=1.4).

For both control groups the exclusion criteria included: 1) the history of any clinically relevant mental disorder; 2 ) underweight or overweight; 3) mental retardation.

Among the subjects included in the database, fifty-one heterosexual men meeting inclusion criteria (age range, 1835 years; mean, 32.41 years; $S D=6.0 ; B M I=21.7, S D=1.8$ ) were included in the control group.

Among the 38 homosexual men who consented to cooperate in the study, 3 were excluded because of current major depression and 9 were excluded because of bisexual behavior. Three homosexual men were excluded because underweight (1 case of Body Mass Index (BMI) <18.5) or overweight (two cases of BMI $>25$ ). Therefore 23 purely homosexual mentally healthy men (age range, 23-48 years; mean, 39.95 years; $S D=9.7 ; B M I=20.8, S D 1.9$ ) matched with the probands for sex, ethnicity and educational level, were included in the homosexual control group. Due to the age distribution of the sample, homosexual controls could not be matched for age, as the previous groups, so age was considered as a confounding factor in the statistical analysis. 


\section{Procedure}

Each patient and heterosexual control underwent a 90-min clinical interview with an experienced psychiatrist who assessed the presence of current or past Axis I mental disorders with the administration of the Structured Clinical Interview for DSM-IV (SCID) [24]. He also administered the Eating Disorder Inventory 2 (EDI-2) [25] to assess eating psychopathology and collected all clinical information required by the study, including the sexual orientation. The EDI was not included in the present study because the homosexual subjects choose not to fill in the test as explained below. The $\mathrm{TCl}$ [26] was administered at the end of the session to the subjects who were included in the study.

Concerning the homosexual subjects, the conditions for cooperating with the research were that no face-to-face interview would have been administered to preserve complete blindness (also for the researchers) about their personal identity, and that no psychopathology questionnaire would have been administered to avoid any possibility of stigmatization of homosexual gender. The recruited subjects were required to declare, beside the informed consent to participate in the study, their age, weight, educational level, and that they were not affected and they had no history of any clinically relevant mental disorder (e.g., that they previously never needed care or medication for any mental disorder). The homosexual subjects were also asked to declare their sexual orientation choosing the definition of purely homosexual or bisexual orientation.

All patients and controls signed a written informed consent, with researchers assuring the patients that their confidentiality was in no way breached. The approval of the study was obtained by the Institutional Review Board of S. Giovanni Battista Hospital of Torino, Italy, where the research was performed. The study was performed according to the principles of the declaration of Helsinki.

\section{Instruments}

The TCl, 240 items adult version [26], is a widely used instrument in the dimensional study of the temperament and character components of personality. It is divided into seven independent dimensions, four of which test temperament and are thought to be related to biologic substrates.

Novelty Seeking (NS) expresses the level of activation of exploratory activity and is mainly related to dopaminergic activity. $\mathrm{HA}$ reflects the efficiency of the behavioral inhibition system, mediated by serotonin. RD refers to behavior maintenance based on rewards and is mainly related to norepinephrine. Persistence expresses maintenance of a behavior as resistance to frustration and is related to glutamate activity.

The remaining three dimensions test character and are considered acquired personality traits. Self-Directedness (SD) expresses the subject's attitudes regarding the individual self, self-acceptance, and the capacity to direct his own life according to individual objectives and values. Cooperativeness is related to attitudes toward relationships with others, social acceptance, tolerance, and the capacity to cooperate. Self-Transcendence (ST) expresses the relationship between the individual and the world, considered in holistic terms as nature, spirituality, and art.

The $\mathrm{TCl}$ displays good internal consistency and reasonable testretest correlation at 6 months [26] and was successfully applied to the study of personality traits of EDs $[10,11]$. In particular the Cronbach Alphas of the major dimensions range from 0.65 for persistence to 0.89 for cooperativeness. Test-retest correlations range from 0.50 for cooperativeness to 0.75 for self-transcendence. We demand to the manual for further information on psychometric properties (https://53d8ec870cf2e38c6331c2ee.pdf).

\section{Data analysis}

The mean age, years of education and BMI were compered using the ANOVA. The TCl scores of the three groups were compared with the general linear model analysis of variance (GLM ANCOVA) using age as confounding factor and the Bonferroni t test as a post-hoc test.

In addition, two discriminant analyses corrected for unequal group sizes were performed with the $\mathrm{TCl}$ dimensions to test the ability of personality traits to predict the classification of subjects to each group. In the first analysis, all groups were included in the statistical elaboration; in the second analysis the men with AN were considered as ungrouped cases and were assigned to either of the control groups on the basis of their personality traits. Statistical analyses have been performed using SAS (SAS Institute Inc, Carey, North Carolina, Release 6.11, 1996).

\section{Results}

\section{Results of GLM ANCOVA}

The HA of anorectic patients ( $80^{\circ}$ percentile rank) and homosexual controls ( $75^{\circ}$ percentile rank) was significantly higher than that of heterosexual controls $\left(50^{\circ}\right.$ percentile rank) $(P<0.052)$. The RD of the homosexual controls ( $45^{\circ}$ percentile rank) was significantly higher than that of men with $A N\left(20^{\circ}\right.$ percentile rank) $(P<0.013)$. The Persistence of homosexual controls ( $15^{\circ}$ percentile rank) was significantly lower than that of men with AN $\left(55^{\circ}\right.$ percentile rank) $(P<0.039)$. The SD of anorectic patients $\left(10^{\circ}\right.$ percentile rank) was significantly lower than that of heterosexual controls $\left(95^{\circ}\right.$ percentile rank) $(P<0.003)$. The Cooperativeness of men with AN ( $9^{\circ}$ percentile rank) was significantly lower than that both control groups $\left(35^{\circ}\right.$ percentile rank for homosexual controls and $40^{\circ}$ percentile rank for heterosexual controls) $(P<0.001)$ (Table 1).

\section{Discriminant analysis with grouped and ungrouped cases}

This procedure has discrete efficacy $\left(1^{\text {st }}\right.$ function canonical correlation $=0.51 ; 2$ nd function canonical correlation $=0.40$ in the first analysis with a $67 \%$ of correct classification; 1 st function canonical correlation $=0.46$ in the second analysis with $77 \%$ of correct classification). Table $\mathbf{2}$ indicates the rates of classification of each group obtained in the first analysis. In the second analysis men with anorexia nervosa, without their original classification, are slightly more likely to fall into the heterosexual control group $(56 \%)$ than into the group of homosexual controls (44\%). 
Table 1 ANOVA among clinical variables and ANCOVA controlled for age among $\mathrm{TCl}^{\mathrm{a}, \mathrm{b}}$.

\begin{tabular}{|c|c|c|c|c|c|c|c|}
\hline & $\mathrm{AM}(\mathrm{N}=21)$ & $\mathrm{HoC}(\mathrm{N}=23)$ & $\mathrm{HeC}(\mathrm{N}=51)$ & \multirow{2}{*}{$F$} & \multirow{2}{*}{$\mathbf{P}$} & \multirow{2}{*}{$\varepsilon^{2}$} & \multirow{2}{*}{ Differences } \\
\hline & $M \pm S D$ & $M \pm S D$ & $M \pm S D$ & & & & \\
\hline Age (yy) & $27.2 \pm 5.7$ & $39.95 \pm 9.7$ & $32.41 \pm 6.0$ & 18.55 & 0 & 0.154 & $\mathrm{AM}<\mathrm{HeC}<\mathrm{HoC}$ \\
\hline School (yy) & $12.7 \pm 2.9$ & $12.9 \pm 3.2$ & $12.4 \pm 2.5$ & 0.28 & 0.756 & 0.007 & - \\
\hline BMI & $16.4 \pm 1.4$ & $20.8 \pm 1.9$ & $21.7 \pm 1.8$ & 69.69 & 0 & 0.437 & $\mathrm{AM}<\mathrm{HeC}, \mathrm{HoC}$ \\
\hline NS & 18.95 .8 & 18.98 .1 & 17.96 .3 & \multirow{2}{*}{0.48} & \multirow{2}{*}{0.38} & \multirow{2}{*}{0.012} & \multirow{2}{*}{-} \\
\hline Percentile & $45^{\circ}$ & $45^{\circ}$ & $40^{\circ}$ & & & & \\
\hline $\mathrm{HA}$ & 18.88 .3 & 17.57 .7 & 13.36 .6 & \multirow{2}{*}{3.06} & \multirow{2}{*}{0.052} & \multirow{2}{*}{0.07} & \multirow{2}{*}{$\mathrm{AM}, \mathrm{HoC}>\mathrm{HeC}$} \\
\hline Percentile & $80^{\circ}$ & $75^{\circ}$ & $50^{\circ}$ & & & & \\
\hline $\mathrm{RD}$ & 12.14 .3 & 14.94 .1 & 13.53 .3 & \multirow{2}{*}{4.56} & \multirow{2}{*}{0.013} & \multirow{2}{*}{0.101} & \multirow{2}{*}{$\mathrm{AM}<\mathrm{HoC}$} \\
\hline Percentile & $20^{\circ}$ & $45^{\circ}$ & $25^{\circ}$ & & & & \\
\hline$P$ & 5.61 .9 & 4.22 .0 & 4.71 .8 & \multirow{2}{*}{3.37} & \multirow{2}{*}{0.039} & \multirow{2}{*}{0.061} & \multirow{2}{*}{$\mathrm{AM}>\mathrm{HoC}, \mathrm{HeC}$} \\
\hline Percentile & $55^{\circ}$ & $15^{\circ}$ & $55^{\circ}$ & & & & \\
\hline SD & 22.09 .4 & 26.48 .3 & 30.59 .4 & \multirow{2}{*}{6.19} & \multirow{2}{*}{0.003} & \multirow{2}{*}{0.133} & \multirow{2}{*}{$\mathrm{AM}<\mathrm{HeC}$} \\
\hline Percentile & $10^{\circ}$ & $15^{\circ}$ & $95^{\circ}$ & & & & \\
\hline C & 23.211 .0 & 30.35 .0 & 31.15 .6 & \multirow{2}{*}{7.27} & \multirow{2}{*}{0.001} & \multirow{2}{*}{0.152} & \multirow{2}{*}{$\mathrm{AM}<\mathrm{HeC}, \mathrm{HoC}$} \\
\hline Percentile & $9^{\circ}$ & $35^{\circ}$ & $40^{\circ}$ & & & & \\
\hline ST & 13.15 .3 & 15.67 .2 & 13.96 .8 & \multirow{2}{*}{1.18} & \multirow{2}{*}{1.609} & \multirow{2}{*}{0.038} & \multirow{2}{*}{-} \\
\hline Percentile & $15^{\circ}$ & $30^{\circ}$ & $20^{\circ}$ & & & & \\
\hline
\end{tabular}

${ }^{a} A M:$ Men affected by Anorexia Nervosa; HoC: homosexual control men; HeC: heterosexual control men; NS: Novelty Seeking; HA: Harm Avoidance; RD: Reward Dependence; P: Persistence; SD: Self-Directedness; C: Cooperativeness; ST: Self-Transcendence.

${ }^{b}$ All scores are indicated as mean \pm standard deviation (SD) rush scores of each TCl dimension; bold characters indicate extreme scores compared to heterosexual controls.

In italics they are indicated the corresponding percentiles of the normal distribution for each $\mathrm{TCl}$ score in the normative sample of the test [26].

\section{Discussion}

Men affected with AN are clearly differentiated from both homosexual and heterosexual controls as personality traits. A clear point of contact is the high HA. Also as it concerns the SD both men with anorexia and homosexual men display a very low percentile rank, even though only men with anorexia display a significantly lower SD compared to heterosexual controls. HA and SD are "core" traits in EDs $[26,27]$ as well as in many other mental disorders [30]. The high HA describes individuals as fearful, tense, apprehensive, nervous, discouraged, insecure, passive, and pessimistic [26]. They tend to react with anxiety, depression, and major signals of stress to potentially harmful stimuli, both environmental and relational ones [27]. Low SD describes them as weak, blaming, impulsive, unreliable, and poorly integrated when they are not conforming to the direction of a mature leader [26]. This evidence may suggests that both men with anorexia and homosexual men may share higher sensibility towards external negative experiences and lower resilience, which may result in higher risk of developing ED or distress in general. On the other hand, since it is not clear at what degree these personality traits pre-exist or represent a reaction to stressful situations [30] in our homosexual controls they may also represent a reaction of to environmental stressors and social cues which are not specific risk factors for EDs development. More in general the present evidences support that there are more personality features which distinguish men with anorexia from homosexual controls than those who they share.

Men with AN display a lower cooperativeness compared to both control groups and a significantly lower RD and a higher persistence compared to homosexual controls. The poor emotional dependence on other people and the scarce development of character traits oriented to an adequate social integration are characteristic of men with $A N$ and not shared with women affected with anorexia nervosa, and hetero or homosexual healthy controls $[7,10,11]$. This evidence supports recent research that sustains a possible different pathway leading from personality traits to the ED outburst in the two sexes $[9,11,12]$.

Concerning overlaps and differences between three subgroups, there are two different evidences that have to be underlined. On one hand none specific affinity between people with AN and homosexual controls is highlighted while it seems to exist a greater affinity between men with anorexia and heterosexual men.

On the other hand, even though it is only the higher HA which significantly differentiates hetero and homosexual controls, the last ones also display strong tendency towards higher levels of $\mathrm{RD}$ and lower levels of persistence and SD. Such profile may imply that a high sensibility towards social issues represents the major motivation to their actions compared to the tendency to persist or SD. Based on research on female patients this configuration of traits may represent a risk factor for homosexual population to the development of mental disorders, EDs included [6,12,15,17,22], in the face of familial [28] and social [21] stressful environmental. Nevertheless since our homosexual controls are not affected with any mental disorder we could also argue that despite the evidences on female samples their high RD may instead represent a protective factor which markedly differentiates them from men affected with AN [7,10,11]. 
Table 2 Group reclustering by discriminant analysis ${ }^{\mathrm{a}}$.

\begin{tabular}{|c|c|c|c|c|}
\hline \multicolumn{5}{|c|}{ Predicted Group Membership } \\
\hline Samples & $\begin{array}{c}\text { Actual } \\
\text { Distribution }\end{array}$ & AM & HoC & HeC \\
\hline AM & $21(22 \%)$ & $15(72 \%)$ & $3(17 \%)$ & $2(11 \%)$ \\
\hline HoC & $23(24 \%)$ & $4(17 \%)$ & $14(61 \%)$ & $5(22 \%)$ \\
\hline HeC & $51(54 \%)$ & $7(13 \%)$ & $9(19 \%)$ & $35(69 \%)$ \\
\hline Total & $95(100 \%)$ & $26(27 \%)$ & $26(27 \%)$ & $42(44 \%)$ \\
\hline
\end{tabular}

Correctly classified: $67.37 \%$

${ }^{a} A M$ : Men affected by anorexia nervosa; HoC: homosexual control men; $\mathrm{HeC}$ : heterosexual control men.

\section{Conclusions}

The specific personality pattern of the men with AN $[10,11]$ does not evidence a specific affinity with that of healthy homosexual men. If a homosexual orientation may produce a predisposition to the development of an ED in males it seems not to derive from a personality trait which strictly resembles that of men with anorexia nervosa, but only for higher $\mathrm{HA}$ and a trend towards lower SD, which is a generic risk factor for, or reaction to mental suffering [30]. This possibly explains the higher liability of healthy homosexual men to mental suffering with respect to heterosexual men $[6,14]$.

Some authors maintain that the femininity [12] may be the more specific risk factor for the anorexia in homosexual subjects [6] because of the higher social pressure towards slenderness on female population [29]. The homosexual orientation and the higher social and relational cues consequent to higher RD and cooperativeness which are related to it may thus explain the "choice" of an ED instead of a more "masculine" mental disorder (i.e., drug dependence or antisocial behaviors). Nevertheless, since the men with AN display an unusually low $\mathrm{RD}$ and cooperativeness with respect to healthy homosexual and heterosexual men, it is possible that particularly in men a pattern of low social adaptation represents a specific risk factor for the development of anorexia nervosa. On the contrary, the high RD of healthy homosexual men may represent a protective factor, provided that they perceive social acceptance and positive adaptation.
As a clinical remark, the data emerging from present research underline the relevance of pro-social personality traits for males affected with AN $[6,14]$. In particular the development of higher $\mathrm{RD}$ and cooperativeness in young men may be useful to prevent the development of ED symptoms. On the other hand, further studies on clinical outcomes are needed to confirm that a specific therapeutic focus on social and relational issues (e.g., either in psychotherapy or in therapeutic communities) may represent a straightforward strategy to produce better symptoms outcome in the male population affected with EDs.

At the same time, the evidences from this study indicate the opportunity to develop a specific screening and prevention programme (e.g., either in school or in other reality) on male population, since the risk factors contributing the development of an ED may be significantly different than in female population.

Further studies are needed to assess gender specific characteristics (femininity/masculinity) in men with $\mathrm{AN}[6,14]$ and the $\mathrm{TCl}$ personality pattern of homosexual men with $A N$ to confirm present findings. The use of the only $\mathrm{TCl}$ instrument is a relevant limitation for the generalization of the results and the possibility of suggesting a specific relationship between personality traits and eating psychopathology in homosexual men. Even if male anorexia subtypes seem to display less personality differences than female anorexia subtypes [11], larger samples are needed to assess the restrictor and binge-purging men with $A N$ separately. Moreover, the small sample of homosexual men is not representative of all the heterogeneous homosexual population. The fact they asked not to be examined by an interviewer as it was made for the probands and the heterosexual controls does not permit to exclude a possible selection bias, also because they may have participated for personal interest in EDs. Finally, the voluntary basis of the recruitment for homosexual controls could have biased the $\mathrm{TCl}$ profile of this group.

\section{Acknowledgments}

We wish thank Dr. Franco Sicca for his help in the recruitment and assessment of the homosexual participants. 


\section{References}

1 Andersen AE (1999) Gender-related aspects of eating disorders: a guide to practice. J Gend Specif Med 2: 47-54.

2 American Psychiatric Association (1994) Diagnostic and statistical manual of mental disorders (4th edn). Washington (DC), Am Psychiatr Assoc.

3 Wo M, Lau J, Rubinstein M (2016) Eating disorders in adolescent and young adult males: presenting characteristics. J Adolesc Health 59: $397-400$

4 Robb AS, Dadson MJ (2002) Eating disorders in males. Child Adolesc Psychiatr Clin N Am 11: 399-418.

5 Woodside DB, Garfinkel PE , Lin E , Goering P, Kaplan AS, et al. (2001) Comparison of men with full or partial eating disorders, and women with eating disorders in the community. Am J Psychiatry 158: 570574.

6 Carlat DJ, Carmago CA Jr, Herzog DB (1997) Eating disorders in males: a report on 135 patients. Am J Psychiatry 154: 1127-1132.

7 Striegel-Moore RH, Garvin V, Dohm FA, Rosenhek R (1999) Psychiatric comorbidity of eating disorders in men: a national study of hospitalized veterans. Int J Eat Disord 25: 399-404.

8 Kinasz K, Accurso EC, Kass AE, Le Grange D (2016) Does sex matter in the clinical presentation of eating disorders in youth? J Adolesc Health 58: 410-416.

9 Grabhorn R, Kopp W, Gitzinger I, von Wietersheim J, Kaufhold J (2003) Differences between female and male patients with eating disorders - results of a multicenter study on eating disorders. Psychother Psychosom Med Psychol 53: 15-22.

10 Fassino S, Abbate Daga G, Leombruni P, Amianto F, Rovera G, et al. (2001) Temperament and character in Italian men with anorexia nervosa. J Nerv Ment Dis 189: 788-794.

11 Woodside DB, Bulik CM, Thornton L, Klump KL, Tozzi F, et al. (2004) Personality in men with eating disorders. J Psychosom Res 57: 273278.

12 Meyer C, Blissett J, Oldfield C (2001) Sexual orientation and eating psychopathology: the role of masculinity and femininity. Int J Eat Disord 29: 314-318.

13 Cai A, Lou Y, Long Q, Yuan J (2016) The sex differences in regulating unpleasant emotion by expressive suppression: extraversion matters. Front Psychol 7: 1011.

14 Russell CJ, Keel PK (2002) Homosexuality as a specific risk factor for eating disorders in men. Int J Eat Disord 31: 300-306.
15 French SA, Story M, Remafedi G, Resnik MD, Blum RW (1996) Sexual orientation and prevalence of body dissatisfaction and eating disordered behaviors: a population-based study of adolescents. Int J Eat Disord 19: 119-126.

16 Hospers HJ, Jansen A (2005) Why homosexuality is a risk factor for eating disorders in males. Journal of Social and Clinical Psychology 24: 1188-1201.

17 Heffernan K (1996) Eating disorders and weight concern among lesbians. Int J Eat Disord 19: 127138.

18 Schneider JA, Agras WS (1995) Gender, sexual orientation and disordered eating. Psychological Health 10: 113-128.

19 Mangweth B, Pope HG Jr, Kemmler G, Ebenbichler C, Hausmann A, et al. (2001) Body image and psychopathology in male bodybuilders. Psychother Psychosom 70: 40-43.

20 Murnen SK, Smolak L (1997) Femininity, masculinity, and disordered eating: a meta-analytic review. Int J Eat Disord 22: 231-242.

21 Stronski Huwiler SM, Remafedi G (1998) Adolescent homosexuality. Adv Pediatr 45: 107-144.

22 Lewis RJ, Derlega VJ, Berndt A, Morris LM, Rose S (2001) An empirical analysis of stressors for gay men and lesbians. J Homosex 42: 63-88.

23 Ludlow LH, Mahalik JR (2001) Congruence between a theoretical continuum of masculinity and the Rasch model: examining the Conformity to Masculine Norms Inventory. J Appl Meas 2: 205-226.

24 Spitzer RL, Williams JB, First M (1990) Structured clinical interview for DSM-III-R. Washington, DC: American Psychiatric Press.

25 Garner DM (1993) Eating disorder inventory-2 professional manual. Odessa, FL, Psychological Assessment Resources.

26 Cloninger CR, Przybeck TR, Svrakic DM, Wetzel RD (1994) The temperament and character inventory: a guide to its development and use. St. Louis, MO: Centre for Psychobiology of Personality.

27 Cloninger CR, Svrakic DM (1999) Personality disorders. In Sadock, V.A., Sadock, B.J. (Edn), Kaplan and Sadock's comprehensive textbook of psychiatry ( $7^{\text {th }}$ edn, pp: $\left.1723-1764\right)$. New York: Lippincott Williams $\&$ Wilkins.

28 Lax RF (1997) Some roots of persistent homosexual fantasy and the quest for father's love: conflicted parental identifications in a male patient: fragment of analysis. Psychoanal Rev 84: 843-863.

29 Gendall KA, Joyce PR, Sullivan PF, Bulik CM (1998) Personality and dimensions of dietary restraint. Int J Eat Disord 24: 371-379.

30 Fassino S, Amianto F, Sobrero C, Abbate Daga G (2013) Does it exist a personality core of mental illness? A systematic review on core psychobiological personality traits in mental disorders. Panminerva Med 55: 397-413. 